\title{
PPP VERSUS MER: SEARCHING FOR ANSWERS IN A MULTI-DIMENSIONAL DEBATE
}

\author{
DETLEF P. VAN VUUREN ${ }^{1}$ and KNUT H. ALFSEN ${ }^{2}$ \\ ${ }^{1}$ Netherlands Environment Assessment Agency, MNP \\ E-mail:Detlef.van.Vuuren@mnp.nl \\ ${ }^{2}$ Research Department, Statistics Norway \\ E-mail: knut.alfsen@ssb.no
}

\section{Introduction}

In 2000, Nakicenovic et al. published a set of new baseline scenarios (Special Report on Emission Scenarios, SRES) in response to a request from IPCC to develop reference scenarios (without explicit climate policies) (Nakicenovic, 2000). These scenarios aimed to cover a significant portion of the possible trajectories of future greenhouse gas (GHG) emissions and their driving forces on the basis of the scenarios in the literature. The scenarios were developed using six of different integrated assessment models, most of them with a more-or-less physical-orientation towards the description of the drivers of future GHG emissions (energy system models; physically oriented integrated assessment models). Consistent with most of the existing literature, the economic growth in most of the SRES scenarios and their regions were reported in US dollars based on conversions using market-exchange rates (MER).

In 2003, however, the use of MER-based economic projections in SRES were subject to criticism, primarily from Castles and Henderson (see, for example, (Castles and Henderson, 2003b; Castles and Henderson, 2003a; Henderson, 2005). The main thrust of this criticism is linked to the assumption made in (some of) the SRES scenarios that relative income per capita levels across regions partially converge over the scenario horizon. According to the critics, the per capita income should be compared by using purchasing power parities (PPP) to more properly compare the actual welfare levels in the different regions. By using market exchange rates, the economic activity levels in developing (non-OECD) regions generally appear to be lower than they actually are when measured in PPP units (as shown in Figure 1). Thus, according to the critics, using MER to reach convergence leads to overstated economic growth in the poorer regions in the scenarios and, as a result, excessive growth in energy demand and emission levels.

A team of SRES researchers responded to this criticism, indicating that in their view, the use of MER or PPP data did not in itself lead to totally different emission projections, and that the use of PPP data was complicated (and probably still is) by 


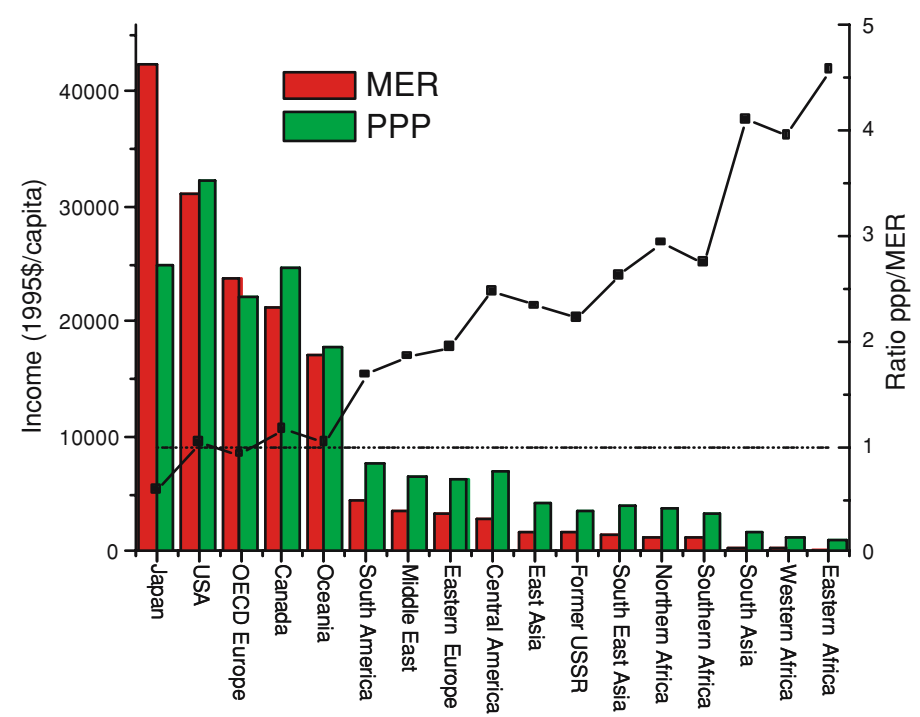

Figure 1. Regional GDP per capita numbers in 1995 in MER and PPP on the basis of World Bank data aggregated to 17 global regions. The left $y$-axis and columns compare absolute data, while the right $y$-axis and line graph compare ratio between PPP and MER data.

lack of data (Nakicenovic et al., 2003; Grübler et al., 2004). They further pointed to one of the SRES scenarios based on a hybrid approach (Nakicenovic et al., 2000), reported both in MER and PPP. Other researchers too have indicated their opinion on this issue or explored it in a more quantitative sense (e.g., Manne and Richels, 2003; McKibbin et al., 2004a; Holtsmark and Alfsen, 2005; Tol, 2006).

The debate on this issue could clearly be important for climate policy. Thus far, the majority of the models used for developing greenhouse gas emission scenarios or estimating costs levels for abatement actions, use MER-based monetary numbers as part of their calculations. More specifically, almost all economic general equilibrium models are MER-based. The more energy-oriented, partial equilibrium models also use MER numbers in a majority of cases, although a few PPP-based or hybrid models also exist. Unfortunately, despite the possible importance of the debate and the fact that the issue can be further explored in a scientific way, the debate itself has up to now not always been very scientific. Most of the criticism has not been published in peer-reviewed journals, the issue has been misused by some to discredit the research on climate change, in general, and the IPCC process, in particular. Furthermore, some of the responses from IPCC had a defensive tone that did not contribute to furthering the debate on the issue of which metric to use.

Fortunately, some exceptions exist. For instance, the recent Energy Modelling Forum provided an opportunity to further elaborate the scientific questions and answers involved. The same goes for the time devoted to the subject at IPCC workshops on scenario development in Amsterdam and Washington (early 2003 and early 2005) - and also for some of the publications currently available. We 
are convinced that for some aspects of this issue the final answers are still not available (Tol's contribution to this issue also leaves important questions open). Only by organising the debate into scientific (sub-)questions, and analysing and exploring these, can progress be made. In this contribution, we will try to take a few steps along this path by subdividing the main issue into several sub-questions to see whether we can find evidence to answer those.

In our view, the debate can be split into a few main strands:

- First of all, there is the question of whether economic development paths in SRES are reasonable or even plausible? How do convergence assumptions relate to this?

- Second, what is the right measure of economic growth in international comparison? Are MER-based models appropriate for developing economic scenarios?

- Third, there is the question of whether the choice of MER versus PPP as an exchange rate metric influences the projected emission levels.

- Fourth, the issue of PPP versus MER may have implications for other issues relevant to climate policy.

\section{The Economic Growth Rates in the SRES Scenarios and the Issue of Convergence}

Although not strictly a PPP-MER question, some of the criticism simply questions the realism of some of the high economic growth rates reported in the SRES scenarios. This issue can in turn be subdivided into two sub-questions:

- Are the economic growth rates of SRES scenarios plausible?

- Is convergence a meaningful assumption for future economic growth?

\subsection{THE ECONOMIC GROWTH RATES OF THE SRES SCENARIOS}

Van Vuuren and O'Neill (2006) recently evaluated the assumptions of the SRES scenarios against more recently published scenarios - and to some degree, historical trends. Obviously, this is a limited check on plausibility - as other scenarios do not necessarily form the "truth". In terms of economic growth, these scenarios find the IPCC scenarios to be somewhat more representative of high economic growth scenarios than of low economic growth scenarios (the SRES global growth rates between 2000 and 2015 range from 1.0 to $2.8 \%$ annually, while more recent projections range from 1.2 to $2.3 \%$; over the whole 2000-2100 period, the numbers are respectively $2-3 \%$ and $1.7-2.8 \%$ ). The IPCC SRES growth assumptions specifically for the Latin America-Africa-Middle East regions are, as a set, higher than most other projections. This study does not lead to a conclusion, however, that global economic growth is dramatically overestimated in SRES. 


\subsection{USING (PARTIAL) CONVERGENCE AS A SCENARIO ASSUMPTION}

The SRES scenarios loosely mention convergence as one of the leading themes in 2 of the 4 scenario families (in SRES, the term convergence is used more-orless synonymous with global integration). At the same time, the relative gap in all scenarios between low and high income regions decreases. There is a very wide range of literature on the question of whether income convergence is a logical attribute of larger economic systems and whether such convergence can actually be observed in the past. There is evidence of convergence within large regional markets, which act more or less as a common market. Examples are the European Union and the USA (Quah, 1996; Sala-i-Martin, 1996). Similar evidence on convergence is found within groups of low-income countries, such as Western Africa (Jones, 2002). Whether convergence occurs globally is more controversial, and depends partly on the methodology used (e.g. Ben-David, 1996; Pritchett, 1997). Over the last decades Asia (low-income) has experienced higher growth rates than the OECD (high-income) average. At the same time, Latin America and, in particular, Africa have not contributed to any global convergence.

While historical evidence is inconclusive, most scenarios on future economic growth assume higher growth rates for low-income region than for high-income regions (probably driven by globalisation assumptions). As such, the SRES scenarios are thus more similar to examples of common practice than exceptions to such practice. The storylines of the scenarios developed by IPCC clearly suggest convergence in at least 2 of the 4 cases. The degree of convergence, also within the total set of SRES scenarios, is obviously open to debate. More important, the scenario growth rates need to be elaborated and evaluated in terms of plausible pathways for the underlying determinants of economic growth (for example, in the SRES context; see (De Vries et al., 2000)).

On the basis of the considerations above, we should note that it would seem reasonable for new literature to explore further what impact very low growth scenarios or scenarios without convergence have on emissions. Such scenarios can already be found in literature - but with diverging results.

\section{The Right Measure of Economic Growth in International Economic Scenarios}

\subsection{ARE ECONOMIC GROWTH RATES REPORTED IN MER APPROPRIATE}

Metrics of economic growth (like any other metric) are developed for certain purposes - and so are the three metrics normally used for expressing income levels: local currencies, PPP and MER numbers. Of these, the most relevant metric for a specific country are the growth numbers measured in local currencies. This is mainly because these represent prices actually observed by actors within the country - and 
therefore guide their decisions and budgets. However, in an international context metrics are needed that relate different local currencies to each other. For this purpose, the MER methodology has traditionally been applied for a number of reasons. First of all, there is an important pragmatic consideration; i.e., that MER numbers are observable and therefore better available and less uncertain than alternative measures aimed at correcting for purchasing power differences. In fact, important methodological barriers still exist in developing a complete set of PPP based numbers covering both the consumption and production side of the economy. Second, for many purposes MER numbers are not only sufficient, but can also be the right choice. This is, in particular, the case for applications where internationally tradable goods (traded in MER) play an important role. In other cases, PPP numbers may be preferable, for instance, if the aim is to describe welfare differences between countries in very different stages of economic development, but also if a true measure of differences in activity among different countries is sought.

On the question of whether PPP or MER should be employed in economic scenario work, the debate at the moment seems to be fully open - where both theoretical and pragmatic considerations play a role. While Castles and Henderson proposed to use only PPP numbers, Nordhaus (2005), for instance, recommends, for principle and practical reasons, a hybrid approach. An important pragmatic reason for Nordhaus not to recommend full use of PPP numbers is that a full, consistent set of economic data to run economic models (like the GTAP database) is still lacking. In the hybrid approach, economic growth scenarios should be constructed by using regional or national accounting MER-based figures (including growth rates) for each region, but using PPP exchange rates for aggregating regions. Therefore, as an alternative, the PPP rates should be updated over time by using a superlative price index, for instance, the Törnqvist index. In contrast, Timmer (2005) actually prefers the use of MER data in long-term modelling. His main argument is that in a model, economic growth should be modelled with relevant observable prices. Within a region, these are mostly domestic prices and across regions, MER-based numbers. PPP would create another set of prices that is not observable.

\subsection{WHAT IS THE CAUSE OF DIFFERENCES BETWEEN PPP-BASED AND MER-BASED INCOME?}

Interestingly enough, in the debate so far very little attention has been paid to the cause of the difference between PPP and MER numbers in the dynamic context of the models. In the literature, different reasons have been postulated for the existence of price differences between countries, global regions and even within countries. The most commonly used theorem explains differences in terms of productivity differences between traded goods and non-traded goods and services. High productivity (and thus high-income levels) in traded goods and services also leads to higher wages in labour-intensive, non-traded goods and services and thus to rel- 
atively high prices for these goods and services. Given the fact that these are not internationally traded, their price differences persist (this is also called the BalassaSamuelson hypothesis). However, there are alternative explanations that explain differences in relation to: (1) size of the informal sector (and a formalisation process), (2) a higher level of capital inflows, resulting in currency appreciation, (3) relative differences in the abundance of money, (4) changes in demand for goods and services as a function of income, which impacts the consumer price index or (5) the impacts of protective trade policies. Which of these explanations are true, will clearly have consequences for the productivity gains possible within a country. We would strongly favour dedicated models that provide more insight into these issues in the context of the present debate on long-term growth potential (and consequences for emissions). Some attempts are already being made by (McKibbin et al., 2004a; Bagnoli, 2005).

\subsection{IN GENERAL}

We personally feel that scientific debate on the issue of right metrics for economic modelling still has to continue, while further research is necessary to facilitate better and more comprehensive PPP data sets and to develop economic development models with PPP metric to complement now predominantly models specified in MER. Clearly, the right choice of metric (MER or PPP) in economic projections depends on the issues one is seeking to elaborate, with MER being preferable where international market conditions are in focus, and PPP being preferable when welfare comparisons are the goal (at least when welfare is dominated by domestic market transactions). In the short term, several economic projections will possibly adopt the suggestions made by Nordhaus. Most economic models, however, are likely to continue using MER-based configurations, if only for data availability reasons. In any case, it is important that a consistent set of numbers is used in model construction (estimation and calibration) and scenario development. We do not feel competent ourselves to add much more to this debate.

\section{Does the Choice of MER Versus PPP as Exchange Rate Metric Influence the Projected Emission Levels?}

When it comes to the emission scenarios, the question is how a shift from MER to PPP numbers, in combination with convergence, would change emissions in general, and in the context of SRES, more specifically. We believe that the impact will be very small, if any. The reason for this is that at the base level, emissions are related to physical activities in manufacturing and the service industries, and in consumption. These activities are usually aggregated within a country using monetary unit; a national or regional emission coefficient is calculated by comparing base-year emissions with base-year economic activity measures in monetary units 
(most models will work with energy intensity and then a factor relating emissions to energy use, which does not change the argument). In theory, different metrics could be used to aggregate - and the best aggregates are those that are either most closely related to the variable of interest (here emissions) or to other variables studied (e.g., welfare effects). Monetary activity data seem to be most attractive in this respect.

The economic activity is then projected into the future on the basis of assumed or modelled development in the labour force, capital stock, productivity of the input factors, etc., as is the development of the emission coefficients. At the end of the simulation period, these entities are combined to produce emission levels measured in physical units. The point is that while the choice of metric for the economic activity will clearly influence the numerical value of that activity, it will also affect the numerical values of emission coefficients. The important factor is that consistent metrics need to be used throughout. Small changes are possible, for a start because calibration of the underlying model will be somewhat different but these small changes could go in both directions.

The argument is illustrated below using regional data for 1995 for both GDP and energy use. Figure 2 plots the energy intensity (the ratio between energy use and GDP) against income measured in MER (left) and PPP (right). In both cases, there seem to be a crude relationship - with high-income countries having a lower ratio than low-income countries. However, the actual values change from MER (left) to PPP (right), with the energy intensity of developing countries dropping by a factor of 4 or so (the difference in energy intensity between high and low income regions is in the order of 2-10 for MER numbers and in the order of 2-3 for PPP numbers). So that while switching from MER to PPP could give different insights into possibilities for monetary economic growth in developing regions (less "room for growth"), it also directly changes insights into possible efficiency improvement (less
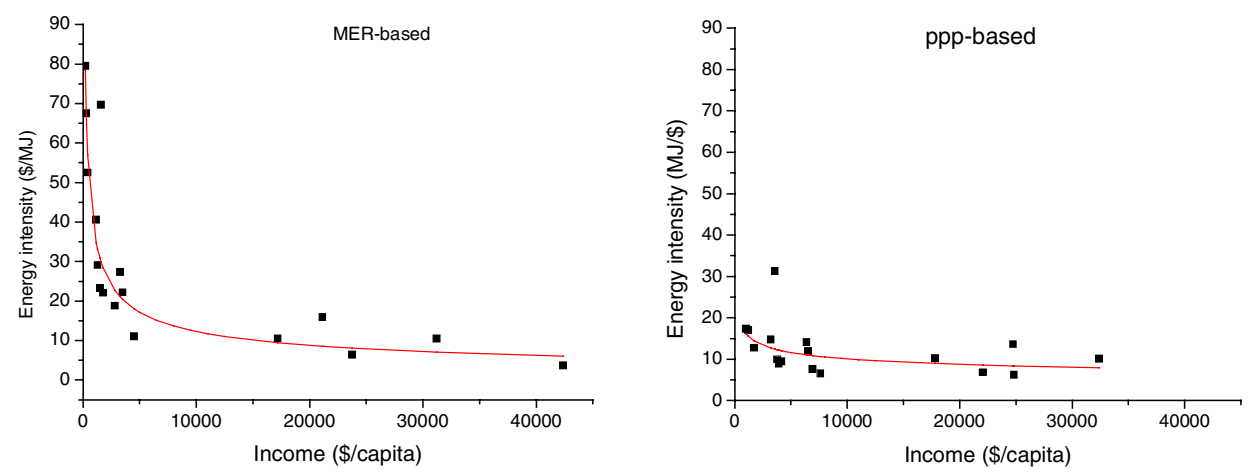

Figure 2. Energy intensity versus income levels for 17 World Regions (1995 data) based on MER and PPP based GDP numbers. The lines indicate the suggested relation (for 1995) between income and energy intensity. The change of metric does not only influence the interpretation of growth rates for income convergence, but also the growth rates for energy intensity convergence. 
efficiency improvement possible). It is unlikely that there is a substantial change in the assessment of total energy use by switching metrics in a consistent manner.

Nevertheless, Manne and Richels (2003), McKibben et al. (2004a; McKibbin et al., 2004b) and Dixon and Rimmer (2005) have, in their modelling work, found some differences in emission levels between using PPP and MER-based estimates, as a result of counteracting influences in their models. Detailed analysis of their work shows that these results critically depend on the interpretation of convergence assumptions made in SRES. More importantly, not all relationships within the model seem to have been adjusted for the switch in metrics. Manne and Richels (2003) change their model from MER to PPP by, first of all, decreasing the economic growth rates of developing countries. This automatically slows down some of the efficiency improvements, as their equation for autonomous efficiency improvement includes GDP growth as one constituent. However, as far as we understand it, no further changes are made; all fundamental model relationships have in fact been calibrated on MER data. McKibben et al. (2004a; McKibbin et al., 2004b) does more-or-less the opposite by running a PPP-based model on the basis of adjusted economic growth rates.

In their simple theoretical model, Holtsmark and Alfsen (2005) showed that consistent replacement of the metric for economic activities (PPP for MER) - for income levels and for underlying technology relationships - leads to a full cancellation of the impact of metric choice on projected emission levels. While using PPP values might give rise to lower economic growth rates for developing countries under the convergence assumption - it will also have an impact on the relationship between income and demand for energy, with lower economic growth leading to slower improvements in energy intensities.

Finally, it should be noted that in the comparison of the outcomes of PPPbased (e.g., POLES/IEA) to MER-based models in the literature no fundamental difference in emission growth rates is observed; this is consistent with our view that if a consistent calibration is used, no fundamental difference is found. In physical terms (e.g., energy per capita) the pathways depicted by SRES also do not seem implausible.

Clearly, a switch from PPP to MER numbers will require changes in the model for a large number of aspects (technology improvement, elasticities etc. etc.). In our view, it would be a useful exercise to see whether this can be done consistently in different types of models.

\section{PPP and MER and Other Issues Relevant to Climate Policy: Mitigation and Adaptation Potential}

Tol (2006) provides an important extension to the literature by raising the problem of how to assess the mitigation and adaptation potentials of countries. This clearly depends on the state of the economy, and as we have seen, on the kind of metric 
used to compare and aggregate regions. Furthermore, mitigation and adaptation, in particular in developing countries, may to a degree depend on access to goods and services traded on the world market in addition to domestic resources. The size of the economy measured in MER gives an indication of the purchasing power of the economy on the world markets, while PPP is best suited to assessing the domestic resource base.

A crucial question for mitigation is whether mitigation technology will be developed locally or will be traded at international markets. The consequences for prices could be large. Examples of both cases exist: windmills in India will typically be locally produced. On the other hand, PV cells in projects in developing countries will often be bought on international markets. Furthermore, conventional power plants can be more costly in developing countries because they include major components bought at international prices even though some of the components and labour costs are local and thus lower.

Similar difficult questions could apply to impact studies. While studying the impact of climate change (and climate change policy) in North Scandinavia, for instance, impacts on oil and gas industries should be in MER as nearly all oil and gas is exported - while other more domestic impacts might be better captured by PPP. The exact ratio for converting impacts (for comparison with other regions) thus may depend on the distribution of impacts across tradable and non-tradable goods. It is therefore difficult at this stage to provide clear guidance on what to use in cases where mitigation and adaptation is at the core of studies.

To some degree, again, consistent replacement of all model parameters is likely to lead to cancellation of the impacts of a PPP-MER switch. To what degree is something that needs to be explored.

\section{Conclusions and Discussions}

In this contribution, we have tried to entangle the debate on how exchange rates influence emission scenarios in various separate issues - all of which can be explored further. We agree with Tol's conclusion (2006) that the influence of exchange rates is a result of model imperfections - and that in an ideal, country-level model the choice of exchange rate should not impact the outcomes. We also agree that, as some of the questions posed in this paper can still not be answered, the issue of how to deal with exchange rates is a relevant one. On the most important issue, i.e., the impact of exchange rates on emission scenarios, we are convinced that using PPP-based values instead of MER-based values would at most only mildly change results in terms of physical parameters, such as energy use or greenhouse gas emissions measured in physical units. Important questions remaining are the impact of this debate on long-term economic scenarios (thus the income numbers; not emissions), and how to develop modelling tools and datasets that are able to work on a PPP basis. Tol (2006) points out that the PPP-MER 
choice may be more important when it comes to studying future mitigation and adaptation possibilities in various regions, but further research is clearly required here.

To end our contribution, we also want to bring this issue into the proper perspective. Long-term scenarios are by definition beset by uncertainties and simplification - and the assumptions made by modellers on some of these can have a very large influence on their outcomes for global emissions, mitigation potential and thus on adaptation possibilities. This includes such factors as choice of technology, structural changes in future economies and societal preferences. SRES shows that the difference in technology assumptions alone may result in more than a 300\% difference in 2100 emissions (in A1T versus A1FI scenario) and a similar range for assumptions on structural change (in the $\mathrm{B} 1$ versus $\mathrm{A} 1 \mathrm{~b}$ scenario). These are impacts that go clearly beyond even the largest estimates of the exchange rate substitution. While we have argued that some issues related to PPP-MER deserve further attention, at the same time, we hope that this can be done within the proper context.

\section{Acknowledgements}

The authors would like to thank Bert de Vries, Nebojsa Nakicenovic and Ton Manders for comments on earlier drafts.

\section{References}

Bagnoli, P.: 2005, Personal communication. OECD, Paris.

Ben-David, D.: 1996, 'Trade and convergence among countries', Journal of International Economics 40, 279-298.

Castles, I. and Henderson, D.: 2003a, 'Economics, Emissions Scenarios and the Work of the IPCC', Energy \& Environment 14(4), 415-435.

Castles, I. and Henderson, D.: 2003b, 'The IPCC Emission scenarios: an economic-statistical critique', Energy \& Environment 14(2-3), 159-185 (27).

De Vries, B., Bollen J., Bouwman, L., Elzen M., den, J. M., and Kreileman, E.: 2000, ‘Greenhouse Gas Emissions in an Equity-, Environment- and Service-Oriented World: An IMAGE-Based Scenario for the 21st Century', Technological Forecasting and Social Change 63, 137-174.

Dixon, P. B. and Rimmer, M. T.: 2005, 'Analysing convergence with a multi-country computable general equilibrium model: PPP versus MER', 8rh Annual Conference on Global Economic Analysis, Lübeck, Germany.

Grübler, A., Nakicenovic, N., Alcamo, J., Davis, G., Fenhann, J., Hare, B., Mori, S., Pepper, B., Pitcher, H., Riahi K., Rogner, H., La Rovere, E. L., Sankovski, A., Schlesinger, M., Shukla, R. P., Swart, R., Victor, N., and Jung, T. Y.: 2004, 'Emission scenarios: A final response', Energy \& Environment 15(1), 11-24.

Henderson, D.: 2005, 'The Treatment of Economic Issues by The Intergovernmental Panel on Climate Change', Energy \& Environment 16, 321-326. 
Holtsmark, B. J. and Alfsen, K. H.: 2005, 'PPP-correction of the IPCC scenarios: Does it matter?', Climatic Change 68(1), 11-19.

Jones, B.: 2002, 'Economic Integration and Convergence of Per Capita Income in West Africa', African Development Review 14(1), 18-47.

Manne, A. and Richels, R.: 2003. Market exchange rates or purchasing power parity: Does the choice make a difference in the climate debate. Working paper 03-11. AEI-Brookings Joint Centre for Regulatory Studies.

McKibbin, W. J., Peace, D., and Stegman, A.: 2004a. Long-run projections for climate change scenarios. Lowy Institute, Sydney.

McKibbin, W. J., Pearce, D., and Stegman, A.: 2004b, 'Can the IPCC SRES be improved?', Energy \& Environment 15(3), 351-362.

Nakicenovic: 2000. Special Report on Emissions Scenarios (SRES). Cambridge University Press, Cambridge, UK.

Nakicenovic, N., Grübler, A., Gaffin, S., Jung, T. T., Kram, T., Morita, T., Pitcher, H., Riahi, K., Schlessinger, M., Shukla, P. R., Van Vuuren, D. P., Davis, G., Michaelis, L., Swart, R., and Victor, N.: 2003, 'IPCC SRES revisited: A response', Energy \& Environment 14(2-3), 187-214.

Nordhaus, W. D.: 2005, 'Alternative measures of output in global economic-environmental models: purchaisng power parity or market exchange rates?', IPCC Expert Meeting on Emissions Scenarios, US-EPA, Washington DC.

Pritchett, L.: 1997, 'Divergence, Big Time', Journal of Economic Perspective, 317.

Quah, D. T.: 1996, 'Emperics for Economic Growth and Convergence', European Economic Review 40, 1353-1375.

Sala-i-Martin, X.: 1996, 'Regional cohesion: Evidence and theories of regional growth and convergence', European Economic Review 40, 1325-1352.

Timmer, H.: 2005, 'PPP vs. MER: A view from the World Bank', IPCC Expert Meeting on Emission Scenarios, Washington D.C., IPCC Technical Support Unit WG-III.

Tol, R. S. J.: 2006, 'Exchange rates and climate change: an application of FUND', Climatic Change doi: 10.1007/s10584-005-9003-4.

Van Vuuren, D. P. and O'Neill, B.: 2006, 'The consistency of IPCC's SRES scenarios to 1990-2000 trends and recent projections', Climatic Change, doi: 10.1007/s10584-005-9031-0.

(Received 15 November 2005; in revised form 14 December 2005) 